\title{
Acid Base Disorders in Critically Ill Neonatal Intensive Care Patients and Predicting Survival by the Presence of Deranged Acid-Base Variables
}

\author{
Imteyaz Ahmad ${ }^{1 *}$, Arif Ahmed ${ }^{2}$ and Smita Roy
}

${ }^{1}$ Department of Biochemistry, PGIMER and Dr Ram Manohar Lohia Hospital, New Delhi, India

${ }^{2}$ Pain Management Centre, Singapore General Hospital, Singapore

\begin{abstract}
Objective: The acid base abnormalities are common in neonates with birth asphyxia and sepsis leading to considerable morbidity and mortality and timely assessment and management of these acid-base derangements leads to a better outcome. So, we did a observational study to assess acid base disorders in neonates by using Boston, Copenhagen approach and Stewart approach and the role of the various variables on predicting the acid base status and the worst outcome in neonates.
\end{abstract}

Study design and methods: An observational study was conducted on the samples provided from the neonates with birth asphyxia and sepsis admitted to neonatal intensive care unit (NICU) in the Post Graduate Institute of Medical Education and Research (PGIMER) and Dr Ram Manohar Lohia (Dr RML) Hospital, New Delhi, India. The blood gas analysis, electrolytes, albumin, lactate levels were compared in the two ailments. The presence of acid base disorders were calculated using Copenhagen approach and Stewart method; and the influence of various variables on acid base disorders and outcome were analyzed.

Results: The metabolic acidosis and alkalosis were seen in 1 and 10 patients as per Boston approach and in 18 and 18 patients with Copenhagen approach. The increased anion gap (AG), and low and high strong ion difference (SID) as measured by Stewart approach were seen in 23,21 and 23 neonates respectively. The acid-base status determined by both Copenhagen and Stewart approach were found to be interrelated. For detecting metabolic acidosis the sensitivity of high for high anion gap $(66.67 \%)$ and hyponatremia $(57.89 \%)$, whereas the specificity is high for lactic acidosis $(94.74$ $\%)$, hyperchloraemia (86.99\%) and hyponatremia (81.08\%). The low $\mathrm{PaCO}_{2}(89.4 \%)$ and low SID $(73.68 \%)$ has a high sensitivity for predicting the non-survival, whereas the lactic acidosis $(94.74 \%)$ has the high specificity of predicting the non-survival, followed by hyponatremia (81.08\%), low SID $(75.68 \%)$, hypoalbuminaemia $(70.27 \%)$ and low $\mathrm{PaCO}_{2}$ $(70.27 \%)$.

Conclusion: In neonates with birth asphyxia and sepsis, acid-base disorders are common. Both the approaches are good in determining the acid-base status, but in complicated situation strong ion difference and strong ion gap works better in determining acid-base status. Derangements like low $\mathrm{PaCO}_{2}$, low SID, hypoalbuminaemia, lactic acidosis and hyponatremia are predictors of worst outcome.

Keywords: Metabolic acidosis; Metabolic alkalosis; Base excess; Strong ion difference; Anion gap

\section{Introduction}

For optimal cellular function a stable extracellular $\mathrm{pH}$ is needed [1]. There are several cellular and extra-cellular buffer systems in the body that interacts to maintain a stable extracellular $\mathrm{pH}$. But in neonates to keep a stable extracellular $\mathrm{pH}$ poses a challenge due to the higher production of acids as compared to adults, which is three times higher as compared to adults. The most important extra-cellular buffer system is the bicarbonate buffer system, which increases or decreases the production of $\mathrm{CO}_{2}$ and $\mathrm{HCO}_{3}$ in response to acidosis or alkalosis. The delayed and more sustained response to change in $\mathrm{pH}$ is provided by the kidneys, which cause acidification or alkalization of urine in response to acidosis or alkalosis. Other buffer systems like hemoglobin, phosphate, etc also play an important role in maintaining a stable $\mathrm{pH}$. But in sick neonates, theses buffer systems are not well developed to maintain a stable $\mathrm{pH}$.

Metabolic acids such as carbonic acid or lactate produce protons leading to acid-base abnormalities. Traditionally Henderson Hasselbalch equation has been used find out the $\mathrm{pH}$ and proton concentration, but to classify the acid-base disorders has become imprecise as fails to recognize the importance of other buffer systems, relying only on $\mathrm{HCO}_{3}$ buffer system for maintenance of $\mathrm{pH}$. Later in 1983, Peter Stewart described the other independent determinants of $\mathrm{pH}$ and proton concentration, and this helped in understanding the basis of acid-base abnormalities and their assessment [2]. In Steward model, the proton generation occurs from dissociation of water, influenced by various factors such as $\mathrm{PaCO}_{2}$, Strong ion difference and plasma weak acids [3]. The acid-base abnormalities are very common in critically ill patients. In these patients, due to presence of hypoalbulinemia or unmeasured anions, the assessment of acid-base status with traditional methods may be misleading and often misses the accurate the complicated acid-base abnormalities [3-6].

\section{The boston $\left(\mathrm{CO}_{2}\right.$-Bicarbonate approach)}

It is based on the relationship between $\mathrm{CO}_{2}$ and bicarbonate derived from Henderson-Hasselbach equation [7].

*Corresponding author: Imteyaz Ahmad, Department of Biochemistry, Nursing home laboratory, Room no.20, Dr Ram Manohar Lohia Hospital, Baba Kharak Singh Marg, New Delhi, India PIN 110001, Tel: +919717378390; E-mail: dr.imteyaz579@gmail.com

Received September 16, 2015; Accepted December 17, 2015; Published December 30, 2015

Citation: Ahmad I, Ahmed A, Roy S (2015) Acid Base Disorders in Critically III Neonatal Intensive Care Patients and Predicting Survival by the Presence of Deranged Acid-Base Variables. J Neonatal Biol 5: 207. doi:10.4172/21670897.1000207

Copyright: ( 2015 Ahmad I, et al. This is an open-access article distributed under the terms of the Creative Commons Attribution License, which permits unrestricted use, distribution, and reproduction in any medium, provided the original author and source are credited. 
The Henderson-Hasselbach equation is given as

$$
\mathrm{pH}=\mathrm{pK}+\frac{\log \left[\mathrm{HCO}_{3}^{-}\right]}{\text {Dissolved } \mathrm{CO}_{2}}
$$

In the above equation, the $\left[\mathrm{H}^{+}\right]$and $\mathrm{PCO}_{2}$ are measured directly; the bicarbonate concentration is derived by solving the above equation. This classifies the acid base disorders into six types. Those relating $\mathrm{H}^{+}$ concentration with $\mathrm{CO}_{2}$ are termed as respiratory and those related to $\mathrm{HCO}_{3}$ are termed as metabolic. This equation fails to quantify the metabolic derangement in the same way as it shows the compensation of the respiratory component. Also it fails to measure other acids. The major flaw is that it treats both $\mathrm{CO}_{2}$ and $\mathrm{HCO}_{3}$ as independent variable rather than the interdependent variable.

\section{Standard base deficit/excess (Copenhagen) approach}

It was given by Singer and Hastings in 1948, and later improved by Siggard-Anderson and his colleagues. Standard base excess is a calculated from $\mathrm{P}_{\mathrm{a}} \mathrm{CO}_{2}$ and $\mathrm{pH}$. When the base excess is positive it is termed as alkalosis, while when the base excess is negative or there is base deficit, it is termed as acidosis [1,8-10].

Also base excess can be measured with the help of the below equation from the serum bicarbonate concentration $\left(\left[\mathrm{HCO}_{3}^{-}\right]\right)$and $\mathrm{pH}$.

Base excess $=0.93 \times\left(\left\{\mathrm{HCO}_{3}{ }^{-}\right\}-24.4+14.8 \times(\mathrm{pH}-7.4)\right)$

$\mathrm{BE}-\mathrm{ECF}=\left[\mathrm{HCO}_{3}^{-}\right]-25+16.2(\mathrm{pH}-7.400)$

Anion gap approach: It was described by Emmit and Narinsto address the various limitations of Boston and Copenhagen approach.

Anion gap is defined as the difference between the anions and the cations in the blood. Anion gap helps the clinicians to determine the underlying cause of a metabolic acidosis. It also helps in detecting the unmeasured anions. To measure anion gap we take into account only $\mathrm{Na}^{+}$and $\mathrm{K}^{+}$, but other unmeasured cations like Kallium, calcium, magnesium also plays a role. As for anion, $\mathrm{Cl}$ is the predominant anion; but in pathological conditions, unmeasured anions also play a role. Mostly in normal situations, the anion gap is due to the negative charge on albumin and phosphate. Normally the anion gap lies between 12 to $16 \mathrm{meq} / \mathrm{litre}$. If the patient develops acidosis with wide anion gap, then it is caused by unmeasured anions like lactate, ketones; while acidosis where anion gap is normal, then it is due to hyperchloraemia.

$$
\text { Anion gap }=\left(\mathrm{Na}^{+}+\mathrm{k}^{+}\right)-\left(\mathrm{HCO}_{3}^{-}+\mathrm{Cl}^{-}\right)
$$

Further in calculating anion gap, if the serum albumin concentration is abnormal; then the anion gap is corrected using the below equation: [8]

$$
\mathrm{AG}_{\text {corrected }}=\mathrm{AG}_{\text {calculated }}+0.25 \times\left([\mathrm{Alb}]_{\text {normal }}-[\mathrm{Alb}]_{\text {measured }}\right)
$$

Also the $\mathrm{HCO}_{3}$ may changes without the change in other variables. Both base excess/deficit and AG fails to estimate this disturbance.

Strong ions difference and gap (Stewart-Fencl approach): At normal $\mathrm{pH}$, strong ions such as $\mathrm{Na}^{+}, \mathrm{K}^{+}$and $\mathrm{Cl}^{-}$are in the dissociated state and contributes to the $\mathrm{pH}$. Weak acids that contributes to acidbase balance includes albumin, inorganic phosphate and plasma proteins; their concentrations do not change with $\mathrm{pH}$ and are therefore a constant. Finally by calculation of the strong ion gap, we can quantify the effect of these variables on the maintenance of acid-base balance [6].

Strong ion difference is of two types, apparent and effective. Of which, the 'apparent' strong ion difference, $[\mathrm{SID}]_{\mathrm{a}}$, is given by the following equation: [9].

$$
[\mathrm{SID}]_{\mathrm{a}}=\left(\mathrm{Na}^{+}+\mathrm{k}^{+}+\mathrm{Ca}^{+}+\mathrm{Mg}^{+}-\left(\mathrm{Cl}^{-}+\text {Lactate }\right)\right.
$$

Normally an equally opposite charged effective strong ion difference $\left(\mathrm{SID}_{\mathrm{e}}\right.$ ) counterbalances the $\mathrm{SID}_{\mathrm{a}}$ (normal approximately $40-44 \mathrm{meq} / \mathrm{L}$ ). The SID negative charge is mainly derived from the dissociated moieties of plasma proteins (albumin) and phosphate. [10]

$$
\mathrm{SID}_{\mathrm{e}}=\left(\mathrm{HCO}_{3}^{-}\right)+(\text {charge on albumin })+(\text { charge on phosphate })
$$

Weak acids charge depends on $\mathrm{pH}$, and so can be calculated as

$$
\left(\mathrm{Alb}^{-}\right)=(\text {albumin in } \mathrm{gm} / \mathrm{dl}) \times(0.23 \times \mathrm{pH}-0.631)
$$

$($ Phosphate $)=($ phosphate $) / 10 \times \mathrm{pH}-0.47$

The sum of the weak acids (albumin and phosphate) is called as $\mathrm{A}^{\mathrm{TOT}}$ as they exists in both dissociated form ( $\mathrm{A}-$ ) as well as nondissociated form $(\mathrm{AH})$.

The strong ion gap is the difference between the SID and SIDe, which is normally zero; but in situations of acid-base abnormalities there is a presence of difference between $\operatorname{SID}_{a}$ and $\operatorname{SID}_{e}$ leading to increased SIG [11].

Actually strong ion gap does not measure all strong anions, but measures all the anions. This was overcome by the following equation which corrects chloride for free water [12].

$$
\left(\mathrm{Cl}_{\text {corrected }}\right)=\left(\mathrm{Cl}_{\text {observed }}\right) \times\left(\mathrm{Na}_{\text {normal }}\right) /\left(\mathrm{Na}_{\text {observed }}\right)
$$

Chloride to sodium ratio: In metabolic acidosis, the role of hyperchloraemia can be determined by the chloride to sodium ratio. A high $\mathrm{Cl}$ : Na ratio indicates hyperchraemia as the cause, whereas a low ratio abolishes its role in acidosis [13].

Many of the neonates with birth asphyxia and sepsis have multiple problems, and many requires invasive and non-invasive monitoring and ventilator support. Assessment of blood gases forms an important part of maintenance of ventilation, oxygenation and normal acid-base status.

The aim of our study is

a. to assess acid base abnormalities in NICU patients by both Boston, Copenhagen and Stewart approach.

b. to evaluate the role of acid-base abnormalities in predicting the survival in neonates.

\section{Material and Methods}

It is an observational study done on the samples provided for analysis from the critically ill neonates admitted in NICU of Post Graduate Institute of Medical Education and Research (PGIMER) and Dr Ram Manohar Lohia (RML) hospital, New Delhi, India. Ethical clearance was taken from hospital ethical committee. All the samples were routine morning samples taken from an artery for assessment of the acid base disorders of the neonate. The blood samples of the critically ill neonates were analyzed for the presence of acid base disorder using Henderson-Hasselbach equation (Boston approach), base excessdeficit (Copenhagen approach) and Stewart method. Also the effects of other variables such as strong ions, albumin, lactate, chloride, $\mathrm{HCO}_{3}$ on the acid base status were noted. There were no control groups in our study.

\section{Sample size}

The sample size was calculated by keeping the power of study at $80 \%$, and alpha error at 0.05 and correlation at $0.6 \%$, assuming that 
there is about 1000 neonates visiting the NICU of Dr RML hospital every year.

\section{Sample collection}

Heparinised blood sample from artery was obtained with different disease conditions before any intervention was done. Then $2 \mathrm{ml}$ arterial blood was drawn from radial artery of each infant under aseptic condition. Total volume of plasma required for estimation of lactate (5 $\mu \mathrm{l})$ and albumin $(10 \mu \mathrm{l})$ as a residue of syringe obtained after electrolyte estimation. Certain precautions are to obtain samples from heparinised syringes. As BGA analyzer has $\mathrm{Na}$ sensor so $\mathrm{NH}_{4}+$ heparin are used instead of $\mathrm{Na}$ - heparin as it interferes with measurement. Radial artery is preferred for sample collection as from femoral artery there are chances of infection in groin area. The samples were collected from syringe flushed with heparin immediately as there are chances of $\mathrm{pH}$ changes due to heparin.

\section{Instrumentation and principle}

The Nova medical Stat Profile pHOx Plus L blood gas analyzer is used for analysis of samples for following parameters $\mathrm{pH}, \mathrm{PCO}_{2}, \mathrm{PO}_{2}$, $\mathrm{SO}_{2} \%, \mathrm{Hct}, \mathrm{Hb}, \mathrm{Na}^{+}, \mathrm{K}^{+}$, Glu, $\mathrm{Ca}^{++}$, Lactate and $\mathrm{Cl}^{-} \cdot$ Using a unique combination of advanced optical and electrode technology, the Stat Profile pHOx series analyzers offer essential blood gas and critical care test. The six test StatProfile pHOx menu adds measured hematocrit, hemoglobin and oxygen saturation to provide a complete picture of lung function and oxygen status. StatProfile pHOx Plus C offers additional test of chloride and ionized calcium. StatProfile pHOx Plus L menu includes lactate. Nova's auto-cartridge quality control is a totally automated quality control system contained within a single on-board control cartridge. This system combines 3 levels of true controls and software allowing any level of quality control to be run. The controls are run every $12 \mathrm{hrs}$ in our emergency laboratory.

\section{Statistical Analysis}

The statistical analysis was done by using SPSS (Statistical Package for the Social Sciences, version 16, SPSS Inc, Chicago, Illinois, USA) for Windows. The variables were expressed as arithmetic mean and standard deviation. Level of significance was set at $\mathrm{P}$ value $<0.05$. The correlation among the various variables was calculated by Pearson Correlation. The relationship of different variables with the two conditions were analysed using ANOVA. The sensitivity and specificity of the variables are determined by using MedCalc for Windows, version 14.12.0 (MedCalc Software, Ostend, Belgium).

\section{Results}

The study was conducted over a duration of four months and a total 56 samples of neonates were analyzed.

Of the total samples, 34 were from neonates with birth asphyxia and 22 were from sepsis. Table 1 gives the comparative assessment of acid base imbalance in birth asphyxia and sepsis a common diagnosis we encountered in NICU patients.

There was a mortality of about 19 neonates in our study, of which 9 died due to birth asphyxia and rest due to sepsis. There was significant difference $(\mathrm{P}$ value $<0.05)$ between the survivors and nonsurvivors for $\mathrm{PaCO}_{2}$, hematocrit, sodium, $\mathrm{HCO}_{3}$, base excess and Strong Ion difference, which lower $\mathrm{PaCO}_{2}$, lower hematocrit, lower sodium, lower $\mathrm{HCO}_{3}$, lower base excess, lower strong ion difference in nonsurvivors. Also lower $\mathrm{PaCO}_{2}$, hyponatremia, low hemtocrit, low base excess, Low Strong ion difference are correlated to non-survivors ( $\mathrm{P}$ value $<0.05$ ). The sensitivity and specificity of various variables in predicting the survival has been in the Table 2. The low $\mathrm{PaCO}_{2}$ and low SID has a high sensitivity of 89.4 and $73.68 \%$ respectively for predicting the non-survival, whereas the lactic acidosis has the high specificity of predicting the non-survival (94.74\%), followed hyponatremia $(81 \%)$, low SID (75.68\%), hypoalbuminaemia (70.27\%) and low $\mathrm{PaCO}_{2}$ (70.27\%) (Table 3).

According to Boston approach $\left(\mathrm{CO}_{2}-\mathrm{HCO}_{3}\right)$, the acidosis was present in only two neonates, out of which one has metabolic acidosis and while the other has a respiratory acidosis. Whereas 25 neonates had alkalosis, out of which 15 had respiratory alkalosis as compared 10 neonates with metabolic alkalosis.

However, according to Copenhagen approach, both metabolic acidosis and alkalosis was present in 18 neonates each. Out of the 18 neonates with metabolic acidosis, low SID was present in only 7 neonates. High anion gap acidosis was observed in 12 neonates, while other 6 had normal anion gap acidosis. Among the patients with high anion gap acidosis 7 had hyperlactaemia. Hyperlactaemia was observed in 27 neonates, out of which 8 had metabolic acidosis. Also hypoalbuminaemia was observed in 16 neonates, out of which 6 had acidosis. Hypernatremia was found among 20 neonates, out of which 8 had metabolic acidosis (Table 4).

There was significant correlation was seen with base excess and $\mathrm{pCO}_{2}, \mathrm{HCO}_{3}$ and Anion gap.

\begin{tabular}{|c|c|c|}
\hline & Birth asphyxia ( $\mathbf{n = 2 9})$ & Sepsis $(\mathbf{n = 2 7})$ \\
\hline $\mathrm{pH}$ & $7.41 \pm 0.52$ & $7.47 \pm 0.6$ \\
\hline $\mathrm{paCO}_{2}$ & $37.57 \pm 12.71$ & $34.96 \pm 16.58$ \\
\hline $\mathrm{PaO}_{2}$ & $95.13 \pm 54.92$ & $113.93 \pm 57.93$ \\
\hline $\mathrm{SaO}_{2}$ & $87.35 \pm 17.5$ & $91.21 \pm 12.9$ \\
\hline Hematocrit & $35.45 \pm 8.62$ & $32.00 \pm 7.17$ \\
\hline Hemoglobin & $11.73 \pm 2.79$ & $10.63 \pm 2.38$ \\
\hline $\mathrm{Na}$ & $144.51 \pm 17.4$ & $140.69 \pm 16.17$ \\
\hline $\mathrm{K}$ & $3.88 \pm 1.39$ & $3.10 \pm 0.62$ \\
\hline $\mathrm{Ca}$ & $0.79 \pm 0.79$ & $0.86 \pm 0.21$ \\
\hline $\mathrm{Bcef}$ & $-0.655 \pm 8.36$ & $2.304 \pm 11.95$ \\
\hline $\mathrm{SBC}$ & $24.72 \pm 6.4$ & $27.82 \pm 9.8$ \\
\hline $\mathrm{HCO} 3$ & $24.14 \pm 8.21$ & $26.03 \pm 11.82$ \\
\hline Lactate & $2.51 \pm 1.59$ & $2.29 \pm 1.50$ \\
\hline Albumin & $3.52 \pm 0.96$ & $4.04 \pm 0.71$ \\
\hline Chloride & $105.00 \pm 5.19$ & $105.30 \pm 6.49$ \\
\hline Anion Gap & $15.27 \pm 19.07$ & $9.26 \pm 20.12$ \\
\hline $\mathrm{Mg}$ & $1.88 \pm 0.48$ & $1.75 \pm 0.69$ \\
\hline SID & $43.46 \pm 16.02$ & $38.45 \pm 3.41$ \\
\hline Table & & \\
\hline
\end{tabular}

Table 1: Showing the various parameters in birth asphyxia and sepsis.

\begin{tabular}{|c|c|c|c|}
\hline Variables & $\begin{array}{c}\text { Total no. blood } \\
\text { samples }\end{array}$ & $\begin{array}{c}\text { Non-survivors } \\
(\mathbf{n = 1 9 )}\end{array}$ & $\begin{array}{c}\text { Survivors } \\
(\mathbf{n = 3 7 )}\end{array}$ \\
\hline Low $\mathrm{PaCO}_{2}$ & 38 & 17 & 11 \\
\hline Low Base Excess (<-4) & 27 & 8 & 19 \\
\hline Hyperlactaemia & 27 & 8 & 19 \\
\hline Lactic acidosis & 4 & 2 & 2 \\
\hline Low strong ion difference & 23 & 14 & 9 \\
\hline High strong ion difference & 21 & 4 & 17 \\
\hline Hypolabuminaemia & 16 & 5 & 11 \\
\hline Increased anion gap & 23 & 6 & 17 \\
\hline Hypochloraemia & 10 & 2 & 6 \\
\hline Hyperchloraemia & 12 & 4 & 8 \\
\hline Hyponatremia & 18 & 11 & 7 \\
\hline Hypernatremia & 14 & 2 & 12 \\
\hline
\end{tabular}

Table 2: Showing the relationship of acid-base abnormalities with survival. 
Citation: Ahmad I, Ahmed A, Roy S (2015) Acid Base Disorders in Critically III Neonatal Intensive Care Patients and Predicting Survival by the Presence of Deranged Acid-Base Variables. J Neonatal Biol 5: 207. doi:10.4172/2167-0897.1000207

Pge 4 of 7

\begin{tabular}{|c|c|c|}
\hline Variables & Sensitivity & Specificity \\
\hline Low SID & $73.68 \%$ & $75.68 \%$ \\
\hline Low PaCO & $89.47 \%$ & $70.27 \%$ \\
\hline High Anion gap & $31.58 \%$ & $54.05 \%$ \\
\hline Hyperlactataemia & $42.11 \%$ & $48.65 \%$ \\
\hline Lactic acidosis & $10.53 \%$ & $94.59 \%$ \\
\hline Hypoalbuminaemia & $26.32 \%$ & $70.27 \%$ \\
\hline Hyponatremia & $57.89 \%$ & $81.08 \%$ \\
\hline Low Base Excess & $42.11 \%$ & $48.65 \%$ \\
\hline
\end{tabular}

Table 3: Showing the sensitivity and specificity of various variables for determining the non-survival.

\begin{tabular}{|c|c|c|c|}
\hline Variables & $\begin{array}{c}\text { Total no. blood } \\
\text { samples }\end{array}$ & $\begin{array}{c}\text { Metabolic } \\
\text { acidosis } \mathbf{( n} \\
\mathbf{= 1 8}\end{array}$ & $\begin{array}{c}\text { Metabolic alkalosis } \\
(\mathbf{n}=\mathbf{1 8})\end{array}$ \\
\hline Low PaCO & 28 & 18 & 0 \\
\hline Hyperlactaemia & 27 & 8 & 10 \\
\hline Lactic acidosis & 4 & 2 & 0 \\
\hline Low strong ion difference & 23 & 7 & 6 \\
\hline High strong ion difference & 21 & 8 & 7 \\
\hline Hypolabuminaemia & 16 & 6 & 4 \\
\hline Increased anion gap & 23 & 12 & 5 \\
\hline Hypochloraemia & 10 & 2 & 5 \\
\hline Hyperchloraemia & 9 & 4 & 2 \\
\hline Hyponatremia & 18 & 6 & 7 \\
\hline Hypernatremia & 20 & 8 & 6 \\
\hline
\end{tabular}

Table 4: Showing the relationship of acid-base abnormalities according to Copenhagen method with different variables.

The sensitivity and specificity of various variables for detecting metabolic acidosis is given in Table 5. Among them, sensitivity of increased anion gap for detection of metabolic acidosis is $66.67 \%$ and lactic acidosis has the highest specificity (Table 6).

Among the 18 neonates with metabolic alkalosis as determined with base excess $>3 \mathrm{mmol} /$ liter, only 6 had high anion gap. The relationship of metabolic alkalosis and the various variables are given in Table 1. Hypochroraemia was observed in 10 neonates, out of which 5 had metabolic alkalosis. Hyponatremia was found among 18 neonates, among them 7 had metabolic alkalosis. The sensitivity and specificity of various variables in detecting metabolic alkalosis was given in table 3. Among them, the sensitivity was low among the variables to detect metabolic alkalosis, whereas hypochloraemia has a high specificity of $86.84 \%$ (Table 7).

There was a great discrepancy in the acid-base status measured by the both Copenhagen approach and Stewart approach. There was about 18 neonates with acidosis as determined by low base excess $(<-3)$; but out of them only 7 had a low SID. Whereas there was 23 neonates with low SID, but out of them only 16 had a normal base excess. Also the discrepancy was seen in the alkalosis also. There were about 18 neonates with metabolic alkalosis as determined by high base excess; but out of them only 7 had high SID. Whereas 21 neonates had a high SID, but out of them normal base excess was found only in 14 patients.

There was significant correlation between $\mathrm{pH}$ and $\mathrm{PaO}_{2}$ and $\mathrm{SaO}_{2}$, lower $\mathrm{pH}$ values have a lower $\mathrm{PaO}_{2}$ and $\mathrm{SaO}_{2 ;}$ and vice versa ( $\mathrm{p}$ value $<0.05$ ). Also the $\mathrm{pH}$ is related to hemoglobin and hematocrit levels, lower $\mathrm{pH}$ is associated with higher hemoglobin and hematocrit levels ( $\mathrm{p}$ value $<0.05$ ).

In our study we have found a significant correlation between $\mathrm{pH}$ and $\mathrm{K}+(\mathrm{p}$ value $<0.05)$, alkalosis is associated with a lower $\mathrm{k}+$ concentration as compared to normal concentration in physiological $\mathrm{pH}$. Also there has been a significant correlation between serum lactate concentration and $\mathrm{pH}$, with higher lactate levels among the neonates with acidosis.

There was significant correlation among $\mathrm{pH}$, anion gap and SID ( $\mathrm{p}$ value $<0.05$ ). The SID and anion gap decreases as the $\mathrm{pH}$ increases in neonates with sepsis, but in neonates with birth asphyxia it remains the same. Also there is strong correlation of $\mathrm{Na}+$ with both SID and anion gap, there is linear change in both anion gap and SID with the change in $\mathrm{Na}+(\mathrm{p}$ value $<0.05)$.

In our study, we have observed that there was significant difference in the $\mathrm{pH}$, albumin and $\mathrm{K}+$ among the neonates with birth asphyxia and sepsis ( $\mathrm{p}$ value $<0.05$ ).

The Figure 1 shows the correlation of base excess (BE) with lactate level in blood as $\mathrm{r}=0.13$, and $\mathrm{p}<0.5$.

Figure 2 depicts the correlation between base excess in extra cellular fluid with $\mathrm{pH}$ with correlation $\mathrm{r}=0.24$ and $\mathrm{p}<0.5$. The correlation of

\begin{tabular}{|c|c|c|c|}
\hline & Non-survivors & Survivors & P value \\
\hline $\mathrm{pH}$ & $7.45 \pm 0.05$ & $7.43 \pm 0.06$ & $>0.05$ \\
\hline $\mathrm{paCO}_{2}$ & $26.39 \pm 12.12$ & $41.41 \pm 13.23$ & $<0.05$ \\
\hline $\mathrm{PaO}_{2}$ & $119.78 \pm 52.23$ & $96.18 \pm 57.86$ & $>0.05$ \\
\hline $\mathrm{SaO}_{2}$ & $92.91 \pm 12.42$ & $87.31 \pm 16.16$ & $>0.05$ \\
\hline Hematocrit & $30.95 \pm 6.91$ & $35.24 \pm 8.32$ & $>0.05$ \\
\hline Hemoglobin & $10.28 \pm 2.28$ & $11.67 \pm 2.71$ & $<0.05$ \\
\hline $\mathrm{Na}$ & $132.87 \pm 14.71$ & $147.7 \pm 15.66$ & $<0.05$ \\
\hline $\mathrm{K}$ & $3.33 \pm 0.91$ & $3.59 \pm 1.25$ & $>0.05$ \\
\hline $\mathrm{Ca}$ & $0.83 \pm 0.21$ & $0.82 \pm 0.25$ & $>0.05$ \\
\hline $\mathrm{Bcef}$ & $-3.1 \pm 7.59$ & $4.29 \pm 8.52$ & $<0.05$ \\
\hline $\mathrm{SBC}$ & $21.78 \pm 6.54$ & $28.49 \pm 8.32$ & $<0.05$ \\
\hline $\mathrm{HCO}$ & $18.71 \pm 8.34$ & $28.31 \pm 9.37$ & $<0.05$ \\
\hline Lactate & $2.71 \pm 1.80$ & $2.24 \pm 1.38$ & $>0.05$ \\
\hline Albumin & $3.77 \pm 0.93$ & $3.77 \pm 0.86$ & $>0.05$ \\
\hline Chloride & $106.43 \pm 6.36$ & $104.48 \pm 5.46$ & $>0.05$ \\
\hline Anion Gap & $7.73 \pm 19.63$ & $14.76 \pm 19.48$ & $>0.05$ \\
\hline Mg & $1.76 \pm 0.42$ & $1.84 \pm 0.43$ & $>0.05$ \\
\hline SID & $29.11 \pm 14.05$ & $47.17 \pm 15.00$ & $<0.05$ \\
\hline Table 5 Show & 2.05 & \\
\hline
\end{tabular}

Table 5: Showing the various parameters in survivors and non-survivors.

\begin{tabular}{|c|c|c|}
\hline Variables & Sensitivity & Specificity \\
\hline Low SID & $38.89 \%$ & $61.11 \%$ \\
\hline High Anion gap & $66.67 \%$ & $70.27 \%$ \\
\hline Hypernatremia & $44.44 \%$ & $68.42 \%$ \\
\hline Hyperlactataemia & $44.44 \%$ & $50.80 \%$ \\
\hline Lactic acidosis & $11.11 \%$ & $94.74 \%$ \\
\hline Hypoalbuminaemia & $33.33 \%$ & $73.68 \%$ \\
\hline Low PaCO & $100 \%$ & $72.97 \%$ \\
\hline Hyperchloraemia & $22.23 \%$ & $86.99 \%$ \\
\hline Hyponatremia & $57.89 \%$ & $81.08 \%$ \\
\hline
\end{tabular}

Table 6: Showing the sensitivity and specificity of various variables for determining the metabolic acidosis as measured by Base-excess-deficit (Copenhagen approach).

\begin{tabular}{|c|c|c|}
\hline Variables & Sensitivity & Specificity \\
\hline High SID & $38.89 \%$ & $58.82 \%$ \\
\hline Hypochloraemia & $27.78 \%$ & $86.84 \%$ \\
\hline Hyponatremia & $38.89 \%$ & $71.05 \%$ \\
\hline
\end{tabular}

Table 7: Showing the sensitivity and specificity of various variables for determining the metabolic alkalosis (by Copenhagen approach). 


\section{$r=0.13, P<0.5$}

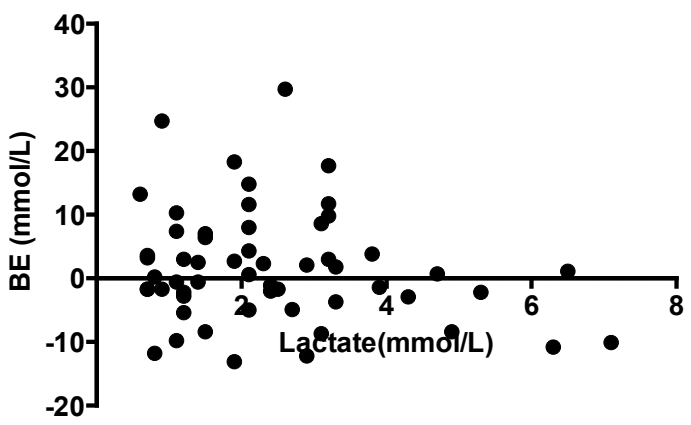

Figure 1: Correlation of base excess and lactate levels in PICU patients with sepsis and Birth Asphixia.

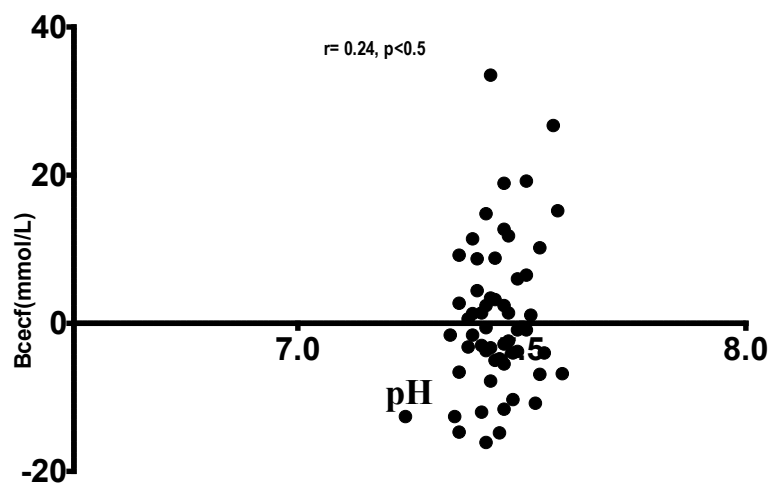

Figure 2: Correlation of base excess in extracellular fluid and $\mathrm{pH}$ levels in PICU patients with sepsis and Birth Asphixia.

serum Albumin and Strong ion difference (SID) is in Figure 3 and the sepsis is associated with hypoalbuminaemia.

In our study we have found that there is a linear relationship between SID and AG and also between SID and $\mathrm{Na}^{+}$, as shown in the Figures 3 and 4 .

The various acid base differences in the birth asphyxia and sepsis are shown in the table I. In birth asphyxia there was comparatively lower $\mathrm{pH}, \mathrm{PaO}_{2}, \mathrm{SaO}_{2}$, base excess, $\mathrm{HCO}_{3}$, albumin than sepsis; whereas sepsis patients was having lower $\mathrm{PaCO}_{2}$, hematocrit , hemoglobin, $\mathrm{Na}$ ,$+ \mathrm{K}+$, lactate, anion gap and SID. There was significant difference in the $\mathrm{pH}$, albumin and $\mathrm{K}^{+}$between birth asphyxia and SID.

\section{Discussion}

The Samples obtained from 56 neonates were analyzed using various approaches to understand the acid-base abnormalities prevalent among the neonates. There was preponderance of male patients with birth asphyxia. There were 19 mortality among the neonates; 9 died due to birth asphyxia and 10 due to sepsis.

Using the Boston approach showed less prevalence of acidosis and more prevalence of metabolic alkalosis. While using Copenhagen approach there was equal number of patients with both alkalosis and acidosis. While Using Stewart approach using SID showed presence of 23 neonates with acidosis and 21 with metabolic alkalosis. Also previously Lekhwani et al. found metabolic acidosis as the predominant acid-base disorder among the neonates [14].

Copenhagen method with base excess works well to determine the acid-base status in uncomplicated situations; but in complicated situations it fails to estimate the acid base status when both the acidifying and alkalinizing disturbances are present.

Base excess/ deficit failed to detect metabolic acid base abnormalities in many of the neonates. Base excess/deficit failed to detect about 14 patients who had a low SID. This may be due to concomitant presence of unmeasured anions, plasma dilution or hyperchloraemia. The alkalizing effects was low albumin may be a contributory factor for the failure of base excess to recognize the low SID. These finding were also observed by Fencl et al., where base excess was found to be normal in about 19 out of 20 patients who had a low SID [15].

In neonates with metabolic acidosis ( $\mathrm{BE}<-3 \mathrm{mmol} / \mathrm{litre}$ ), two third had a high a high anion gap. In critical illness, there is usually concurrent hypoalbuminaemia which covers the metabolic acidosis [16]. Also the unmeasured ions leads to change in anion gap, anions increase, whereas cations decrease the anion gap. So, it is essential to detect the unmeasured anions such as lactate and ketones, and as well as exogenous anions such as formate and glycolate.

Hyperlactaemia was present in 27 neonates; but out of them only 8 was found to have metabolic acidosis. The hyperlactaemia was more prevalent among the neonates with sepsis. Hyperlactataemia is an important feature of sepsis. The mechanism of increase in lactate in sepsis is due to hypermetabolism, whereas in septic shock it is due to hypoxia [17]. Neonates cannot compensate for hyperlactaemia by hyperventilating. Also no correlation between high lactate and $\mathrm{pH}$ or high lactate and base excess was seen. This was similar study by Lekhwani et al. [17].

In neonates, therespiratory alkalosis compensated the metabolic acidosisas interpreted bythe strong correlation of base excess with $\mathrm{pH}$, $\mathrm{pCO}_{2}$ and $\mathrm{HCO}_{3}$. Hypoalbuminaemia was observed in about one third of patients with sepsis and birth asphyxia. Hypoalbuminaemia may be due to decreased albumin synthesis or increased plasma efflux in sepsis. Hyalbuminaemia was not found be a major contributor factor in metabolic alkalosis with its presence in only less than one fourth of neonates with alkalosis. Also no correlation was seen between base excess or SID with albumin. Rossing et al. also found similar results in their study [18].

Neonates with birth asphyxia have a lower $\mathrm{pH}$ and base excess as

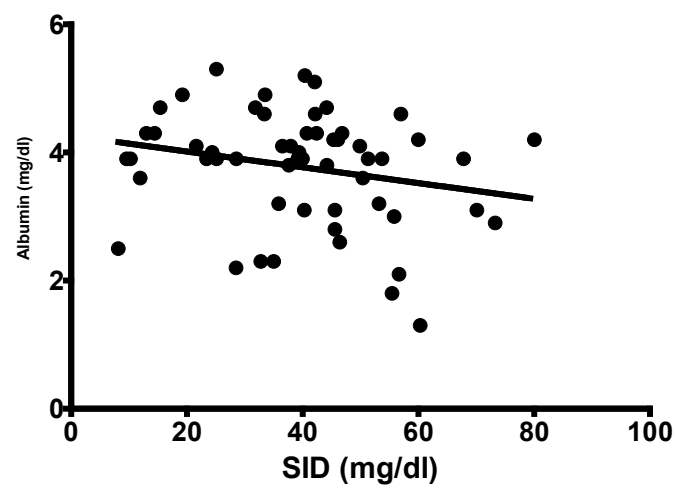

Figure 3: Correlation of Serum Albumin in extracellular fluid and Strong lon Difference (SID) levels in PICU patients with sepsis and Birth Asphyxia. 
compared to neonates with sepsis. Previous studies had also found a low base excess and low $\mathrm{pH}$ among the neonates with sepsis; and Chan et al. proposed that umbilical artery $\mathrm{pH}$ to be below 7.0 as a diagnostic criteria for birth asphyxia $[19,20]$.

Strong correlation of $\mathrm{pH}$ with various variables like base excess, anion gap and SID confirms that there is a strong interrelationship among the acid-base differences asassessed by the various methods. So, this confirms that the acid-base disturbances as assessed by the two methods are actually related to the $\mathrm{pH}$ determined.

The association of lower $\mathrm{pH}$ with lower $\mathrm{PaO}_{2}$ and $\mathrm{SaO}_{2}$, confirms that the tissue hypoxia leading to production of more $\mathrm{H}+$ ions via anaerobic respiration. Also the $\mathrm{pH}$ was normal in patients with normal $\mathrm{PaO}^{2}$ and $\mathrm{SaO}^{2}$. Thus it confirms that the tissue hypoxia is an important contributory factor of metabolic acidosis in neonates.

Our study has also shown that there is a relationship between $\mathrm{pH}$ and $\mathrm{K}+$ concentration. In our study, the higher $\mathrm{pH}$ was associated with lower $\mathrm{k}+$ concentration and vice versa. In acidosis, there was an inward movement of $\mathrm{H}+$ and outward movement of $\mathrm{K}+$ from inside the cell, and with alkalosis the reverse occurs.

Also an interesting finding in our study is that there was a significant correlation between $\mathrm{pH}$ and hemoglobin. With lower $\mathrm{pH}$, there was a higher value of hemoglobin and hematocrit. Hemoglobin is an important intracellular buffer. So, with a lower $\mathrm{pH}$ may be leading to compensatory increased in hemoglobin to maintain the $\mathrm{pH}$ in the neonates. Thus we may assume that hemoglobin buffer has an important role in the maintenance of acid-base balance in neonates, but to confirm further well designed studies are needed.

With Figge-Fencl equations SID can be measured from albumin and phosphate, but in our study we could not use the Figge-Fencl equations as the provision to measure phosphate ions was not available in our analyzer [13].

Standard nomogram is used to correct the base excess for hemoglobin $[9,10]$. A multicompartmental model developed by Wooten is used to correct the Figge-Fencl equations for haemoglobin [21].

In our study, we have found a strong correlation between low $\mathrm{PaCO}_{2}$, low base excess, low HCO, low hematocrit, high anion gap and low SID with non-survival (P value $<0.05$ ). Also presence of these variable has been found to predict the non-survival also to a varying degree. The low $\mathrm{PaCO}_{2}$ and high anion gap has a high sensitivity for predicting non-survival, whereas Lactic acidosis, low base excess and hyponatremia has been found to be more specific in predicting nonsurvival. So, the presence of these variables can help us to predict the non-survival and thus can help us to take more appropriate steps for the survival.

Matthew Martin et al. have also found that corrected anion gap, the strong ion gap and the base deficit corrected for unmeasured anions helps in the prediction of mortality in trauma intensive care patients $[22,23]$. However in another study, Rocktaeschel et al. found that the unmeasured anions in the form of anion gap, anion gap corrected, base excess caused by unmeasured anions, strong ion gap are not accurate predictors of hospital mortality rate in critically ill patients [24]. In another study, Balasubramanyan et al. found that elevated unmeasured anions identified by the Fencl-Stewart method were more strongly associated with mortality than with $\mathrm{BE}, \mathrm{AG}$, or lactate in pediatric patients with critical illness, which strongly confirms our findings [25]. Martin et al. results were similar to our study, as they have found that increased lactate levels predict mortality in the surgical intensive care unit [26]. Mikkelsen ME et al. also found that both intermediate and high serum lactate levels were independently associated with mortality in patients with severe sepsis independent of organ failure and shock, which is similar to our study [27]. Our results contradicts the findings of Ratanarat et al. as in their study they have found that in comparison to traditional approach, the Stewart approach does not provide any greater advantage to predict mortality in critically ill patients [28]. Cusack et al. findings were also similar to our study, as they also have found that SBE, BE (UA,) lactate, $\mathrm{pH}$ and $\mathrm{AG}$ have the best ability to measure the outcome [29].

The limitations in our study are

1. We could not do a randomized control study, as we were not able to get samples from healthy neonates,

2. The contribution of phosphate in acid-base disorders could not be estimated,

3. Samples from neonates with birth asphyxia and sepsis are only taken in the study, so acid-base disorders cannot be generalized for all the neonatal conditions,

4. No follow-up samples were analyzed to assess the changes in the neonates with time,

5. Also no correlation could be done with the morbidity with the acid-base status, only the correlation with mortality has been done.

\section{Conclusion}

In neonates with birth asphyxia and sepsis, acid-base abnormalities are common. Both the approaches are good in measuring the acidbase disorders, but in complicated situations base excess with anion gap failed to measure acid-base disorders. In these situations, Stewart approach is better to determine acid-base disturbances. Although there was a strong correlation among the acid-base status measured by various methods, but many a times there was a discrepancy due to the presence of multiple variables influencing the acid-base status, which is mostly deranged in critically ill neonates. Finally, the variables like low $\mathrm{PaCO}_{2}$, low SID, lactic acidosis, hypoalbuminaemia and hyponatremia helped in predicting the non-survival among the neonates. Further randomized controlled studies with larger sample size are needed to confirm our findings.

\section{References}

1. Kellum JA (2000) Determinants of blood pH in health and disease. Crit Care 4: 6-14.

2. Stewart PA (1983) Modern quantitative acid-base chemistry. Can J Physio Pharmacol 61: 1444-1461.

3. Figge J, Mydosh T, Fencl V (1992) Serum proteins and acid-base equilibria: a follow-up. J Lab Clin Med 120: 713-719.

4. Figge J, Jabor A, Kazda A, Fencl V (1998) Anion gap and hypoalbuminemia Crit Care Med 26: 1807-1810

5. Kellum JA, Kramer DJ, Pinsky MR (1995) Strong ion gap: a methodology for exploring unexplained anions. J Crit Care 10: 51-55.

6. Schwartz WB, Relman AS (1963) A critique of the parameters used in the evaluation of acid-base disorders. "Whole-blood buffer base" and "standard bicarbonate" compared with blood $\mathrm{pH}$ and plasma bicarbonate concentration. N Engl J Med 268: 1382-1388.

7. Andersen OS (1962) The $\mathrm{pH}-\log \mathrm{pCO} 2$ blood acid-base nomogram revised Scand J Clin Lab Invest 14: 598-604.

8. Andersen OS, Engel K (1960) A new acid-base nomogram. An improved 
Citation: Ahmad I, Ahmed A, Roy S (2015) Acid Base Disorders in Critically III Neonatal Intensive Care Patients and Predicting Survival by the Presence of Deranged Acid-Base Variables. J Neonatal Biol 5: 207. doi:10.4172/2167-0897.1000207

method for the calculation of the relevant blood acid-base data. Scand $\mathrm{J}$ Clin Lab Invest 12: 177-186.

9. Andersen OS (1963) Blood acid-base alignment nomogram. Scales for $\mathrm{pH}$, $\mathrm{pCO}_{2}$ base excess of whole blood of different hemoglobin concentrations, plasma bicarbonate, and plasma total- $\mathrm{CO}_{2}$. Scand J Clin Lab Invest 15: 211217.

10. Emmett M, Narins RG (1977) Clinical use of the anion gap. Medicine (Baltimore) 56: $38-54$.

11. Fencl V, Jabor A, Kazda A, Figge $\mathrm{J}$ (2000) Diagnosis of metabolic acid-base disturbances in critically ill patients. Am J Respir Crit Care Med 162: 22462251.

12. Jurado RL, del Rio C, Nassar G, Navarette J, Pimentel JL Jr (1998) Low anion gap. South Med J 91: 624-629.

13. McAuliffe JJ, Lind LJ, Leith DE, Fencl V (1986) Hypoproteinemic alkalosis. Am J Med 81: 86-90.

14. Lekhwani S, Shanker V, Gathwala G, Vaswani ND (2010) Acid-base disorders in critically ill neonates. Indian J Crit Care Med 14: 65-69.

15. Durward A, Mayer A, Skellett S, Taylor D, Hanna S, et al. (2003) Hypoalbuminaemia in critically ill children: incidence, prognosis, and influence on the anion gap. Arch Dis Child 88: 419-422.

16. Bakker J, Nijsten MW, Jansen TC (2013) Clinical use of lactate monitoring in critically ill patients. Ann Intensive Care 3: 12.

17. Rossing TH, Boixeda D, Maffeo N, Fencl V (1988) Hyperventilation with hypoproteinemia. J Lab Clin Med 112: 553-559.

18. Palsdottir K, Dagbjartsson A, Thorkelsson T, Hardardottir H (2007) [Birth asphyxia and hypoxic ischemic encephalopathy, incidence and obstetric risk factors]. Laeknabladid 93: 595-601.

19. Pálsdóttir K, Thórkelsson T, Hardardóttir H, Dagbjartsson A (2007) [Birth asphyxia, neonatal risk factors for hypoxic ischemic encephalopathy]. Laeknabladid 93: 669-673.
20. Chen ZL, He RZ, Peng Q, Guo KY, Zhang YQ, et al. (2006) [Clinical study on improving the diagnostic criteria for neonatal asphyxia]. Zhonghua $\mathrm{Er} \mathrm{Ke} \mathrm{Za}$ Zhi 44: 167-172.

21. Wooten EW (2003) Calculation of physiological acid-base parameters in multicompartment systems with application to human blood. J Appl Physiol (1985) 95: 2333-2344.

22. Martin M, Murray J, Berne T, Demetriades D, Belzberg H (2005) Diagnosis of acid-base derangements and mortality prediction in the trauma intensive care unit: the physiochemical approach. J Trauma 58: 238-243.

23. Rosival V (2005) Diagnosis of acid-base derangements and mortality prediction in the trauma intensive care unit: the physiochemical approach. J Trauma 59: 509.

24. Rocktaeschel J, Morimatsu H, Uchino S, Bellomo R (2003) Unmeasured anions in critically ill patients: can they predict mortality? Crit Care Med 31: 2131-2136.

25. Balasubramanyan N, Havens PL, Hoffman GM (1999) Unmeasured anions identified by the Fencl-Stewart method predict mortality better than base excess, anion gap, and lactate in patients in the pediatric intensive care unit. Crit Care Med 27: 1577-1581.

26. Martin MJ, FitzSullivan E, Salim A, Brown CV, Demetriades D, et al. (2006) Discordance between lactate and base deficit in the surgical intensive care unit which one do you trust? Am J Surg 191: 625-630.

27. Mikkelsen ME, Miltiades AN, Gaieski DF, Goyal M, Fuchs BD, et al. (2009) Serum lactate is associated with mortality in severe sepsis independent of organ failure and shock. Crit Care Med 37: 1670-1677.

28. Ratanarat R, Sodapak C, Poompichet A, Toomthong P (2013) Use of different approaches of acid-base derangement to predict mortality in critically ill patients. J Med Assoc Thai 96 Suppl 2: S216-223.

29. Cusack RJ, Rhodes A, Lochhead P, Jordan B, Perry S, et al. (2002) The strong ion gap does not have prognostic value in critically ill patients in a mixed medical/surgical adult ICU. Intensive Care Med 28: 864-869. 